\title{
Synthesis of 1,2-divinylcyclopropanes by metal-catalyzed cyclopropanation of 1,3-dienes with cyclopropenes as vinyl carbene precursors
}

\author{
Jesús González, Alba de la Fuente, María J. González, Laura Díez de Tejada, \\ Luis A. López ${ }^{*}$ and Rubén Vicente*
}

\author{
Letter \\ Address: \\ Departmento de Química Orgánica e Inorgánica e Instituto \\ Universitario de Química Organometálica "Enrique Moles", \\ Universidad de Oviedo, Julián Clavería 8, 33006-Oviedo, Spain \\ Email: \\ Luis A. López - lalg@uniovi.es; Rubén Vicente* - \\ vicenteruben@uniovi.es \\ ${ }^{*}$ Corresponding author \\ Keywords: \\ cyclopropanation; cyclopropenes; dienes; divinylcyclopropanes; \\ transition metal catalysis
}

Beilstein J. Org. Chem. 2019, 15, 285-290.

doi:10.3762/bjoc. 15.25

Received: 30 October 2018

Accepted: 11 January 2019

Published: 30 January 2019

This article is part of the thematic issue "Cyclopropanes and cyclopropenes: synthesis and applications".

Guest Editor: M. Tortosa

(C) 2019 González et al.; licensee Beilstein-Institut.

License and terms: see end of document.

\begin{abstract}
The synthesis of 1,2-divinylcyclopropanes by the reaction of cyclopropenes with 1,3-dienes is reported. The process relies on the ability of $\mathrm{ZnCl}_{2}$ or $\left[\mathrm{Rh}_{2}(\mathrm{OAc})_{4}\right]$ to generate metal-vinyl carbene intermediates from cyclopropenes, which effect cyclopropanation of 1,3-dienes. Most of the reactions proceeded in reasonable yields while the diastereoselectivity strongly depends on the structure of the diene. An example of an intramolecular process as well as the use of furan and 1,4-cyclohexadiene as dienes are also reported.
\end{abstract}

\section{Introduction}

Far from being considered exotic molecules, cyclopropane derivatives constitute an interesting class of compounds. Indeed, far over 4000 natural products bearing a cyclopropane ring have been discovered [1-3], and cyclopropane-containing molecules are recurrent in medicinal chemistry [4-6]. Likewise, due to its unique structure and bond properties, cyclopropanes have exclusive yet useful synthetic utilities [7], which are closely connected with the substitution pattern. For instance, the pres- ence of vinyl groups directly attached to a cyclopropane ring allows sigmatropic rearrangements leading to odd-numbered carbocyclic derivatives [8]. In this sense, seven-membered carbocycles, namely 1,4-cycloheptadienes, can be forthrightly prepared from cis- or trans-1,2-divinylcyclopropanes through a Cope rearrangement $[8,9]$. The potential of this type of cyclopropanes contrasts with the existence of few straightforward routes for their syntheses. Typical methods rely on the use of 
reagents containing the required cyclopropane ring, which involve multistep sequences for the installation of adequate functionalization. Thus, Wittig-type olefination with cyclopropanecarboxaldehydes [10] or reactions of metallated vinylcyclopropanes with suitable electrophiles are commonly employed (Scheme 1a) [11-13]. In a more convergent approach where the cyclopropane ring is created at the last stage, divinylcyclopropanes can be prepared by cyclopropanation of 1,3dienes with metal-vinyl carbenes generated from vinyldiazoacetates (Scheme 1b) [14-16]. This reaction has been fruitfully exploited, although it is inherently limited by the restricted availability of potentially explosive diazo compounds. Consequently, the use of alternative vinyl carbene precursors is highly desirable to expand the accessibility to 1,2-divinylcyclopropanes [17-19]. In this regard, cyclopropenes have demonstrated to be suitable precursors of metal-vinyl carbenes [20,21], which can be easily trapped with alkenes [22-25]. Our recent studies showed that simple $\mathrm{ZnCl}_{2}$ could be used to generate the corresponding zinc-vinyl carbene to efficiently prepare vinylcyclopropane derivatives with a remarkable broad scope (Scheme 1c) [26]. In view of these precedents, we decided to study the feasibility of this reaction in the synthesis of 1,2-divinylcyclopropanes by using 1,3-dienes as trapping reagents (Scheme 1d). Herein, we present the results of this study.

\section{Results and Discussion}

At the outset, the reaction of cyclopropene $\mathbf{1 a}$ and freshly distilled 1,3-cyclohexadiene (2a, 5.0 equiv) in the presence of $\mathrm{ZnCl}_{2}$ as catalyst was performed under the reaction conditions previously employed for simple alkenes, namely $\mathrm{ZnCl}_{2}$ $10 \mathrm{~mol} \%, \mathrm{CH}_{2} \mathrm{Cl}_{2}$, at ambient temperature (Scheme 2) [26]. Pleasantly, 1,2-divinylcyclopropane 3a was obtained in good yield (81\%) with moderate endo (syn) selectivity (endo/exo $=6: 1$ ). It should be indicated that the preference for the endo isomer has already been observed in related reactions [17]. Other metals capable of promoting both carbene generation from cyclopropenes and cyclopropanation reactions were also evaluated. Interestingly, when $\left[\mathrm{Rh}_{2}(\mathrm{OAc})_{4}\right](1.0 \mathrm{~mol} \%)$ was employed, compound 3a was isolated in $71 \%$ yield, a slightly lower value when compared to $\mathrm{ZnCl}_{2}$, but more importantly, with complete endo (syn) selectivity. The use of gold,

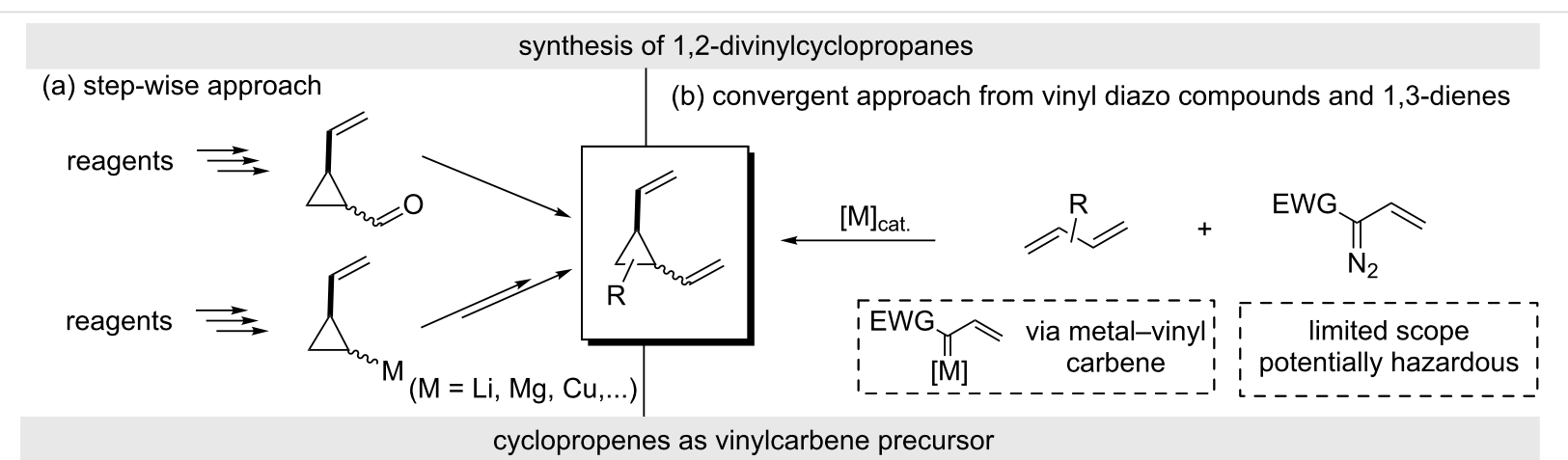

(c) vinylcyclopropanes from alkenes [20-25]

(d) 1,2-divinylcyclopropanes from 1,3-dienes: this study
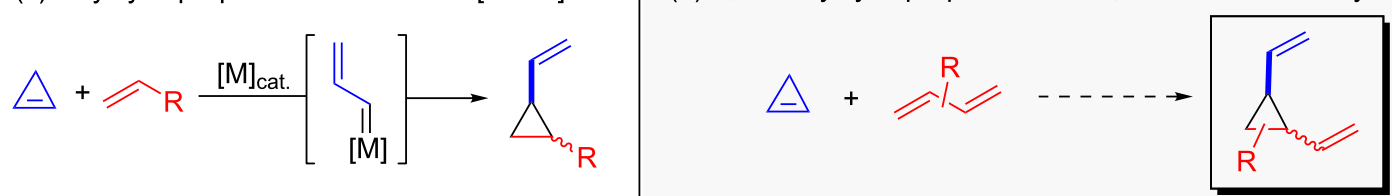

Scheme 1: Typical syntheses of 1,2-divinylcyclopropanes and rationale hypothesis for their syntheses from cyclopropenes and 1,3-dienes.

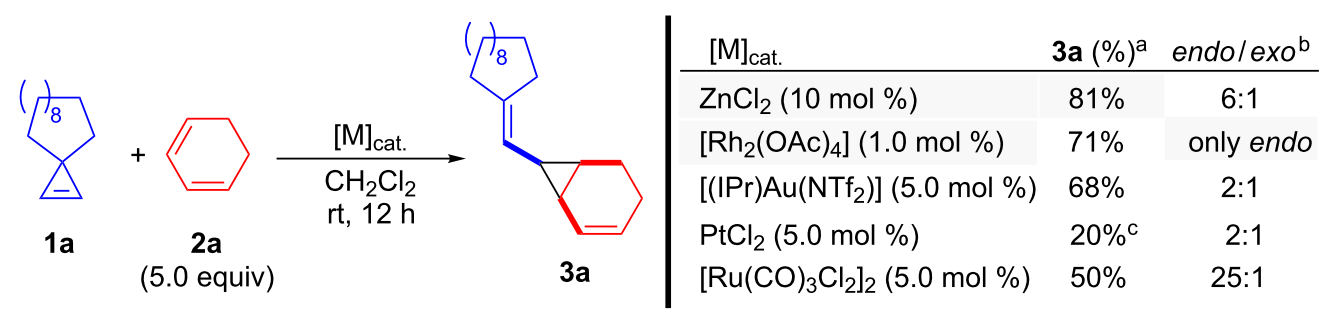

Scheme 2: Synthesis of 1,2-divinylcyclopropane 3a: Optimization studies. ${ }^{a}$ Isolated yield. ${ }^{b}$ Determined by ${ }^{1} \mathrm{H}$ NMR on the reaction crude mixture (unaltered after purification). ${ }^{c}$ Estimated by ${ }^{1} \mathrm{H}$ NMR. (IPr = 1,3-bis(2,6-diisopropylphenylimidazol-2-ylidene). 
platinum or ruthenium catalysts showed poorer results with respect to reaction yield and endo/exo (syn/anti) selectivity, as indicated in Scheme 2.

Considering these results, the scope of the reaction with unbiased 1,3-dienes was next investigated using both $\mathrm{ZnCl}_{2}$, as it provided the best yield being the most inexpensive catalyst, and
$\left[\mathrm{Rh}_{2}(\mathrm{OAc})_{4}\right]$, since it delivered the best result in terms of selectivity. The results are summarized in Scheme 3.

Using 1,3-cyclohexadiene (2a), the analogous reaction was accomplished with 3,3-dihexyl- (1b) and 3,3-dibenzylcyclopropene (1c). Thus, divinylcyclopropane $\mathbf{3 b}$ was obtained in reasonable yields with both catalysts $(69 \% \mathrm{Zn}$ and $75 \% \mathrm{Rh})$,
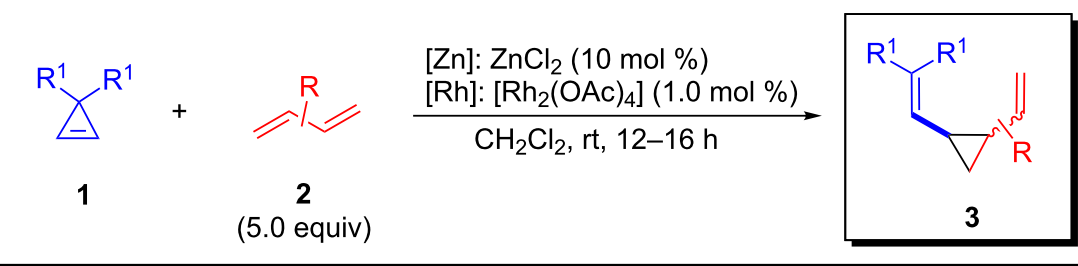

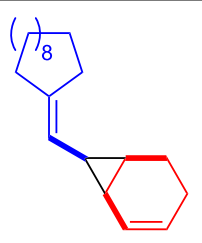

$3 \mathbf{a}$

[Zn]: $81 \%($ endo/exo $=6: 1)$ [Rh]: 71\% (only endo)

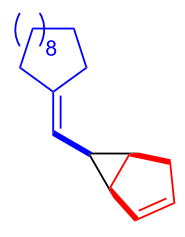

3d

[Zn]: $81 \%($ endo/exo $=15: 1)$ [Rh]: 90\% (only endo)

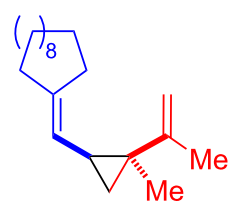

$3 \mathbf{g}$

[Zn]: $80 \%$ (cis/trans $=1.3: 1)$

[Rh]: $88 \%$ (cis/trans = 1:1.2)

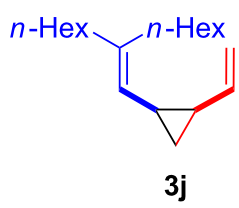

[Zn]: $70 \%(\text { cis } / \text { trans }=2: 1)^{c}$

[Rh]: $67 \%(\text { cis } / \text { trans }=4: 1)^{c}$

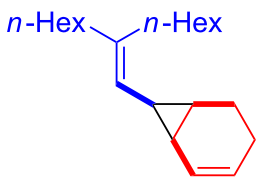

$3 \mathbf{b}$

[Zn]: $69 \%$ (endo/exo $=6.5: 1$ )

[Rh]: $75 \%$ (endo/exo = 17:1)

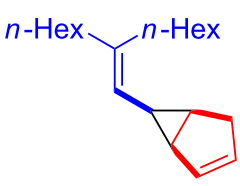

3 e

[Zn]: $84 \%$ (endo/exo $=18: 1)$

[Rh]: $79 \%$ (only endo)

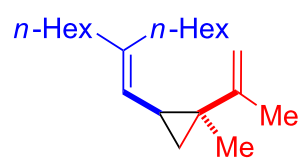

3h

[Zn]: $84 \%$ (cis/trans $=1.3: 1$ )

[Rh]: $79 \%$ (cis/trans $=1: 3.2)$

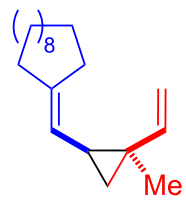

3k

[Zn]: $72 \%$ (cis/trans $=1: 1)$

[Rh]: $83 \%$ (cis/trans $=1.7: 1)$

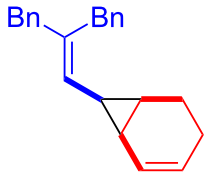

3c

$[\mathrm{Zn}]: 85 \%(\text { endo/exo }=4.5: 1)^{\mathrm{a}}$

[Rh]: (complex mixture) $)^{\mathrm{a}, \mathrm{b}}$

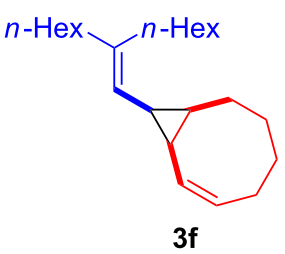

[Zn]: 73\% (endo/exo = 11:1)

[Rh]: $71 \%$ (only endo)

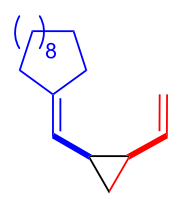

$3 \mathbf{i}$

[Zn]: $78 \%(\text { cis/trans }=2: 1)^{\mathrm{c}}$

[Rh]: $70 \%(\text { cis } / \text { trans }=2.5: 1)^{\mathrm{c}}$

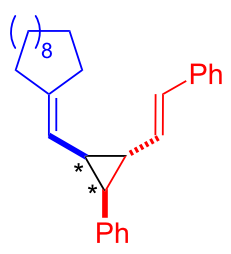

3I

[Zn]: $50 \%(\text { cis } / \text { trans }=2.5: 1)^{\mathrm{d}}$

[Rh]: (complex mixture) ${ }^{\mathrm{b}}$ 
albeit better selectivity was obtained again with rhodium(II) catalyst (endo/exo $=17: 1)$. In contrast, the reaction with $1 \mathrm{c}$ led to the corresponding cyclopropane $3 \mathbf{c}$ only when $\mathrm{ZnCl}_{2}$ was used as catalyst $(85 \%$, endo/exo $=4.5: 1)$ at slightly higher temperature $\left(50{ }^{\circ} \mathrm{C}\right)$. In this case, $\left[\mathrm{Rh}_{2}(\mathrm{OAc})_{4}\right]$ completely failed under different reaction conditions leading inevitably to degradation of starting cyclopropene. Other cyclic 1,3-dienes were then evaluated. For instance, the use of cyclopentadiene in the reaction with $\mathbf{1 a}$ and $\mathbf{1 b}$ enabled the preparation of divinylcyclopropanes 3d,e in good yields. Both catalysts provided similar yields, while complete endo selectivity was only reached with $\left[\mathrm{Rh}_{2}(\mathrm{OAc})_{4}\right]$. Interestingly, the use of $1,3-$ cyclooctadiene led to the formation of compound $\mathbf{3 f}$ ( $\mathrm{Zn}$ : $73 \%$, endo/exo $=11: 1$; Rh: $71 \%$, only endo), in which the 1,2-divinylcyclopropane moiety is embedded within a bicyclo[6.1.0]nonane core. Then, we studied the reaction with various representative unbiased acyclic 1,3-dienes. Unsurprisingly, these substrates could be easily converted into the corresponding 1,2divinylcyclopropanes but with very low selectivities. For instance, when 2,3-dimethyl-1,3-butadiene was employed with cyclopropenes 1a,b, the corresponding 1,2-divinylcyclopropanes $\mathbf{3 g}$,h were prepared in good yields regardless of the catalyst employed. However, $\mathbf{3 g}, \mathbf{h}$ were obtained as an almost equimolar mixture of cis/trans diastereoisomers (cis refers to both vinyl substituents). Even though the lack of selectivity was already noticed by Uemura and co-workers in related reactions [17], we attempted the reaction with other zinc salts or rhodium(II) carboxylates as catalysts. Unfortunately, these experiments were futile and led to similar low selectivities. Besides, gaseous 1,3-butadiene could be also employed, as demonstrated by the preparation of compounds $\mathbf{3 i}, \mathbf{j}$, which were obtained in moderate yields and low cis selectivities. The reaction with isoprene showed a remarkable selectivity for the most substituted alkene, allowing the synthesis of 1,2-divinylcyclopropane $3 \mathbf{k}$ within the typical range of yields and cis/trans selectivities. Finally, 1,2,3-trisubstituted divinylcyclopropane $3 \mathbf{l}$ was prepared in $50 \%$ (cis/trans $=2.5: 1)$ from cyclopropene 1a and $(1 E, 3 E)$-1,4-diphenylbuta-1,3-diene through a stereoselective reaction. Once more, simple $\mathrm{ZnCl}_{2}$ was particularly effective for this reaction in sharp contrast to the incompetence of $\left[\mathrm{Rh}_{2}(\mathrm{OAc})_{4}\right]$.
It should be noticed that 1,2-divinylcyclopropanes $\mathbf{3 a - 1}$ did not undergo [3,3]-Cope rearrangements under the reaction conditions. Moreover, when pure endo-3e was refluxed in toluene $(24 \mathrm{~h})$ partial isomerization was observed (endo/exo $=1: 1.6)$. This behavior can be attributed to the high substitution at one of the alkenes, which might lead to sterically overcrowded transition states required for the rearrangement [27]. Besides, the diastereoisomeric mixture of $\mathbf{3} \mathbf{j}$ suffered complete degradation under the same reaction conditions.

In recent years, Cossy and co-workers elegantly prepared various bicyclo[n.1.0] derivatives through intramolecular cyclopropanation reactions using adequately decorated $1, n$-cyclopropenenes [24]. Hence, we preliminarily explored the feasibility of an analogous reaction with 1,3-dienes preparing dienylcyclopropene 4 . While treatment of 4 with $\mathrm{ZnCl}_{2}$ led to complex mixtures, likely due to the Lewis acid sensitivity of the benzylic cyclopropenylcarbinol moiety, the use of $\left[\mathrm{Rh}_{2}(\mathrm{OAc})_{4}\right]$ $\left(1.0 \mathrm{~mol} \%, \mathrm{CH}_{2} \mathrm{Cl}_{2}, \mathrm{rt}\right.$ ) led to the tricyclic compound 5 in good yield $(77 \%)$ in a stereoctive manner (Scheme 4$)$.

Finally, we were curious to study the reactivity of metal-vinyl carbenes generated from 3,3-disubstituted cyclopropenes with some particular dienes (Scheme 5). Interestingly, we found that the reaction of cyclopropenes $\mathbf{1 a}, \mathbf{b}$ with furan (6) using $\mathrm{ZnCl}_{2}$ as catalyst allowed the isolation of diastereomerically pure endo-7a,b oxabicycles showing the 1,2-divinylcyclopropane moiety. In contrast, $\left[\mathrm{Rh}_{2}(\mathrm{OAc})_{4}\right]$ afforded complex reaction mixtures. In spite of the modest yields, this zinc-catalyzed reaction deserves some comments as it constitutes a rare example of isolation of these structures. Indeed, Lee and co-worker found that the corresponding gold-catalyzed reaction leads to ringopened products through a facile oxy-Cope-rearrangement [28]. Moreover, these structures are also not accessible with metal-vinyl carbenes generated from vinyldiazo compounds, which led again to oxy-Cope rearranged or [4+3]-cycloaddition products using rhodium catalysts [14,28-30], or to a C2-allylation of furan with gold catalysts [31]. Finally, to compare the reactivity of cyclopropenes and vinyldiazo compounds, we probed the reaction of 1 a with 1,4-cyclohexadiene (8). Under otherwise identical reaction conditions, both $\mathrm{ZnCl}_{2}$

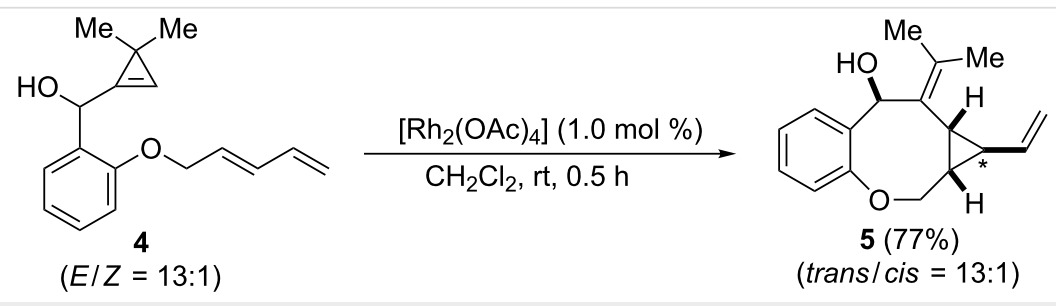

Scheme 4: Rh-catalyzed intramolecular cyclopropanation with dienylcyclopropene 4 (the trans/cis ratio is related to the C-atom labelled with an asterisk). 


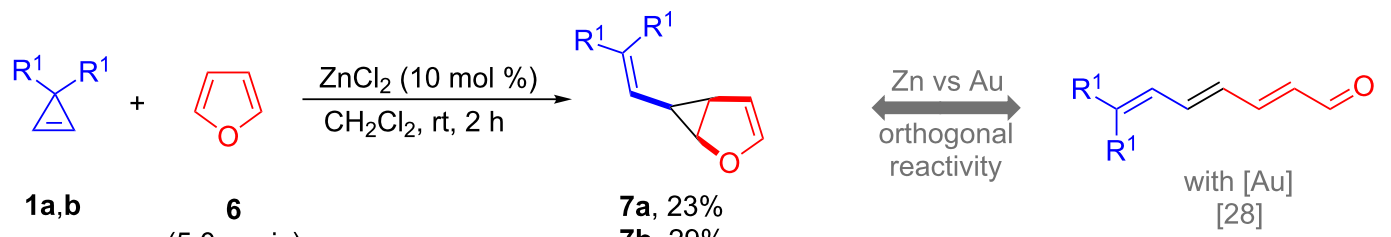

(5.0 equiv)

7 b, $29 \%$
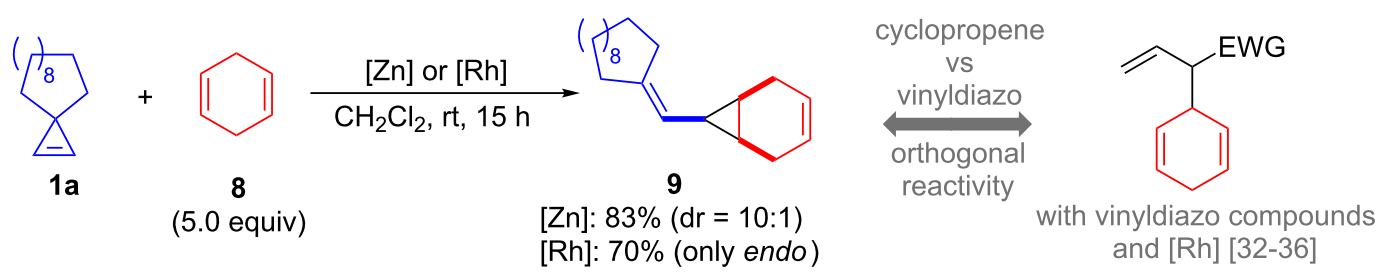

Scheme 5: $\mathrm{Zn}$ - or Rh-catalyzed reactions of cyclopropenes $\mathbf{1}$ with furan (6) and 1,4-cyclohexadiene (8) and comparison with related processes (1b, $\left.\mathrm{R}^{1}=n-\mathrm{Hex}\right)$.

and $\left[\mathrm{Rh}_{2}(\mathrm{OAc})_{4}\right]$ yielded exclusively cyclopropane 9 in practical yields and endo selectivity. This reaction outcome differs from the comparable reactions with vinyldiazo compounds and rhodium(II) catalysts, which preferentially undergo $\mathrm{C}-\mathrm{H}$ allylic insertions [31-35].

\section{Conclusion}

In summary, we have described a straightforward method for the synthesis of 1,2-divinylcyclopropane derivatives by cyclopropanation reactions using unbiased 1,3-dienes and cyclopropenes, which served as metal-vinyl carbene precursors. The use of cyclic dienes allowed the synthesis of the corresponding 1,2-divinylcyclopropanes with good-to-complete endo selectivity. In contrast, acyclic dienes were also efficiently converted into the expected cyclopropanes but with low cis/trans selectivities. In general, simple $\mathrm{ZnCl}_{2}$ and $\left[\mathrm{Rh}_{2}(\mathrm{OAc})_{4}\right]$ proved to be adequate catalysts. An intramolecular version of this reaction is also reported. Finally, the use of other dienes, such as furan and 1,4-cyclohexadiene was explored showing interesting reaction outcomes that are complementary to previous related reports. Subsequent studies to expand the scope of this cyclopropanation reaction to biased 1,3-dienes as well as to increase selectivities are currently ongoing.

\section{Supporting Information}

\section{Supporting Information File 1}

Experimental details as well as ${ }^{1} \mathrm{H}$ and ${ }^{13} \mathrm{C}$ NMR spectra of new compounds.

[https://www.beilstein-journals.org/bjoc/content/ supplementary/1860-5397-15-25-S1.pdf]

\section{Acknowledgements}

Financial support from Ministerio de Economía y Competitividad (MINECO), Agencia Estatal de Investigación (AEI) and Fondo Europeo de Desarrollo Regional (FEDER) (CTQ201676840-R) and Principado de Asturias (grant GRUPIN14-013) is gratefully acknowledged. We thank Prof. J. M. González for his unrestricted support.

\section{ORCID ${ }^{\circledR}$ iDs}

Luis A. López - https://orcid.org/0000-0002-0893-6298

Rubén Vicente - https://orcid.org/0000-0002-3251-1820

\section{References}

1. Chen, D. Y.-K.; Pouwer, R. H.; Richard, J.-A. Chem. Soc. Rev. 2012, 41, 4631-4642. doi:10.1039/c2cs35067j

2. Gnad, F.; Reiser, O. Chem. Rev. 2003, 103, 1603-1624. doi:10.1021/cr010015v

3. Donaldson, W. A. Tetrahedron 2001, 57, 8589-8627. doi:10.1016/s0040-4020(01)00777-3

4. Taylor, R. D.; MacCoss, M.; Lawson, A. D. G. J. Med. Chem. 2014, 57, 5845-5859. doi:10.1021/jm4017625

5. Talele, T. T. J. Med. Chem. 2016, 59, 8712-8756. doi:10.1021/acs.jmedchem.6b00472

6. Gagnon, A.; Duplessis, M.; Fader, L. Org. Prep. Proced. Int. 2010, 42, 1-69. doi:10.1080/00304940903507788

7. Kulinkovich, O. G. Cyclopropanes in Organic Synthesis; John Wiley \& Sons, Inc: Hoboken, NJ, 2015. doi:10.1002/9781118978429

8. Vshyvenko, S.; Reed, J. W.; Hudlicky, T.; Piers, E. Rearrangements of Vinylcyclopropanes, Divinylcyclopropanes, and Related Systems. In Comprehensive Organic Synthesis II; Knochel, P., Ed.; Elsevier, 2014; Vol. 5, pp 999-1076. doi:10.1016/b978-0-08-097742-3.00523-1

9. Krüger, S.; Gaich, T. Beilstein J. Org. Chem. 2014, 10, 163-193. doi:10.3762/bjoc.10.14

10. Marino, J. P.; Kaneko, T. Tetrahedron Lett. 1973, 14, 3975-3978. doi:10.1016/s0040-4039(01)87087-8 
11. Marino, J. P.; Browne, L. J. Tetrahedron Lett. 1976, 17, 3245-3248. doi:10.1016/s0040-4039(00)93892-9

12. Wender, P. A.; Filosa, M. P. J. Org. Chem. 1976, 41, 3490-3491. doi:10.1021/jo00883a043

13. Wender, P. A.; Hillemann, C. L.; Szymonifka, M. J. Tetrahedron Lett. 1980, 21, 2205-2208. doi:10.1016/0040-4039(80)80003-7

14. Davies, H. M. L.; McAfee, M. J.; Oldenburg, C. E. M. J. Org. Chem. 1989, 54, 930-936. doi:10.1021/jo00265a037

15. Cantrell, W. R., Jr.; Davies, H. M. L. J. Org. Chem. 1991, 56, 723-727. doi:10.1021/jo00002a044

16. Davies, H. M. L.; Clark, T. J.; Smith, H. D. J. Org. Chem. 1991, 56, 3817-3824. doi:10.1021/jo00012a011

17. Miki, K.; Ohe, K.; Uemura, S. J. Org. Chem. 2003, 68, 8505-8513. doi:10.1021/jo034841a

18. Takeda, T.; Mori, A.; Fujii, T.; Tsubouchi, A. Tetrahedron 2014, 70, 5776-5786. doi:10.1016/j.tet.2014.06.043

19. Barluenga, J.; Quiñones, N.; Tomás-Gamasa, M.; Cabal, M.-P. Eur. J. Org. Chem. 2012, 2312-2317. doi:10.1002/ejoc.201200149

20. Archambeau, A.; Miege, F.; Meyer, C.; Cossy, J. Acc. Chem. Res. 2015, 48, 1021-1031. doi:10.1021/acs.accounts.5b00016

21. Vicente, R. Synthesis 2016, 48, 2343-2360. doi:10.1055/s-0035-1561644

22. Miege, F.; Meyer, C.; Cossy, J. Org. Lett. 2010, 12, 4144-4147. doi:10.1021/ol101741f

23. Miege, F.; Meyer, C.; Cossy, J. Chem. - Eur. J. 2012, 18, 7810-7822. doi:10.1002/chem.201200566

24. Miege, F.; Meyer, C.; Cossy, J. Angew. Chem., Int. Ed. 2011, 50, 5932-5937. doi:10.1002/anie.201101220

25. Tomilov, Y. V.; Bordakov, V. G.; Tsvetkova, N. M.; Dolgii, I. E.; Nefedov, O. M. Russ. Chem. Bull. 1982, 31, 2129. doi:10.1007/bf00950678

26. González, M. J.; González, J.; López, L. A.; Vicente, R. Angew. Chem., Int. Ed. 2015, 54, 12139-12143. doi:10.1002/anie.201505954

27. Sasaki, T.; Eguchi, S.; Ohno, M. J. Org. Chem. 1972, 37, 466-469. doi:10.1021/jo00968a030

28. Hadfield, M. S.; Lee, A.-L. Chem. Commun. 2011, 47, 1333-1335. doi:10.1039/c0cc04217j

29. Davies, H. M. L.; Clark, D. M.; Alligood, D. B.; Eiband, G. R. Tetrahedron 1987, 43, 4265-4270. doi:10.1016/s0040-4020(01)90301-1

30. Davies, H. M. L.; Calvo, R. L.; Townsend, R. J.; Ren, P.; Churchill, R. M. J. Org. Chem. 2000, 65, 4261-4268. doi:10.1021/jo991959b

31. Barluenga, J.; Lonzi, G.; Tomás, M.; López, L. A. Chem. - Eur. J. 2013, 19, 1573-1576. doi:10.1002/chem.201203217

32. Bykowski, D.; Wu, K.-H.; Doyle, M. P. J. Am. Chem. Soc. 2006, 128, 16038-16039. doi:10.1021/ja066452e

33. Davies, H. M. L.; Stafford, D. G.; Hansen, T. Org. Lett. 1999, 1, 233-236. doi:10.1021/ol9905699

34. Davies, H. M. L.; Antoulinakis, E. G. J. Organomet. Chem. 2001, 617-618, 47-55. doi:10.1016/s0022-328x(00)00599-4

35. Doyle, M. P.; Duffy, R.; Ratnikov, M.; Zhou, L. Chem. Rev. 2010, 110, 704-724. doi:10.1021/cr900239n

\section{License and Terms}

This is an Open Access article under the terms of the Creative Commons Attribution License

(http://creativecommons.org/licenses/by/4.0). Please note that the reuse, redistribution and reproduction in particular requires that the authors and source are credited.

The license is subject to the Beilstein Journal of Organic Chemistry terms and conditions:

(https://www.beilstein-journals.org/bjoc)

The definitive version of this article is the electronic one which can be found at:

doi:10.3762/bjoc. 15.25 